\title{
Video Game Interaction Related to Increased Present Attention in College Students
}

\author{
Radael Rezende Rodrigues Junior ${ }^{1}$ \\ Lívia Rodrigues ${ }^{1}$ \\ Mariane Lima de Souza ${ }^{1}$
}

\begin{abstract}
Action video games require a high level of attention and almost automatic psychomotor reactions from the player. Therefore, this study aims to verify the relationship between the amount of hours of interaction with action video games and private self-awareness and attention to the present moment. In total, 1,315 college students were recruited $(M=21.6$ years; $S D=2.7)$, who responded to the Digital Entertainment and Information Use Questionnaire, the Self-Reflection and Insight Scale, and the Full Attention and Awareness Scale. Statistical analysis (Kruskal-Wallis and Dunn's Post-Hoc Tests) indicated a relationship between hours of video game interaction, attention to the present, and self-reflection. It is concluded that playing action video games regularly and for a certain period of time is related to a lower predisposition to turn attention to oneself and to lower impulsivity, but to a higher disposition to focus on everyday experiences (attention to the present).
\end{abstract}

Keywords: computer games, attention, self perception, college students

\section{Interação com Videogames se Relaciona a Maior Atenção ao Presente em Universitários}

\begin{abstract}
Resumo: Videogames de ação exigem do jogador nível de atenção alto e reações psicomotoras quase automáticas. Portanto, o objetivo do presente estudo foi verificar a relação entre quantidade de horas de interação com videogames de ação e a autoconsciência privada e a atenção ao momento presente. Foram recrutados 1.315 universitários $(M=21,6$ anos; $D P=2,7)$, que responderam ao Questionário de Uso de Entretenimento e Informação Digital, à Escala de Autorreflexão e Insight e à Escala de Atenção e Consciência Plena. A análise estatística (Testes de Kruskal-Wallis e Post-Hoc de Dunn) indicou relação entre quantidade de horas de interação com videogames, atenção ao presente e autorreflexão. Conclui-se que jogar videogames de ação regularmente e por um determinado período relaciona-se a menor predisposição em voltar a atenção para si mesmo e a menor impulsividade, porém à maior propensão a focar experiências cotidianas (atenção ao presente).
\end{abstract}

Palavras-chave: jogos de computador, atenção, autopercepção, estudantes universitários

\section{Interacción con Videojuegos se Relaciona a Más Atención al Presente en Universitarios}

\begin{abstract}
Resumen: Los videojuegos de acción exigen del jugador alto nivel de atención y reacciones psicomotoras casi automáticas. Por lo tanto, el objetivo de este estudio fue verificar la relación entre cantidad de horas de interacción con videojuegos de acción y la autoconciencia privada y la atención al momento presente. Se reclutaron a 1.315 universitarios $(M=21,6$ años; $D E=2,7)$, que contestaron la Encuesta de Uso de Entretenimiento e Información Digital, a la Escala de Autorreflexión e Insight y a la Escala de Atención y Conciencia Plena. El análisis estadístico (Pruebas de Kruskal-Wallis y Post-Hoc de Dunn) indicó una relación entre cantidad de horas de interacción con videojuegos, atención al presente y autorreflexión. Se concluye que quien juega videojuegos de acción regularmente y por determinado período tiene menos predisposición en volver la atención a sí mismo y menos impulsividad, aunque más propensión a enfocarse en experiencias cotidianas (atención al presente).
\end{abstract}

Palabras clave: juegos de computador, atención, autopercepción, estudiantes universitarios

\footnotetext{
${ }^{1}$ Universidade Federal do Espirito Santo, Vitória-ES, Brazil

Article derived from the first author's doctoral thesis under the supervision of the third author, defended in 2021 at the Graduate Program in Psychology at the Federal University of Espírito Santo (UFES). This research was carried out with the support of the Coordenação de Aperfeiçoamento de Pessoal de Nível Superior - Brasil (CAPES) - Financing Code 001.

Correspondence address: Radael Rezende Rodrigues Junior. Universidade Federal do Espírito Santo. Av. Fernando Ferrari, 514, Goiabeiras, Vitoria-ES, Brazil. CEP 29.075-910. E-mail: radael@gmail.com
}

Attention is a selective neurological process of information and stimuli that allows a more productive relationship between the individual and the environment, both internal and external (Eysenck \& Keane, 2017). Due to its high complexity, this construct is generally categorized into subtypes based on the way the organism selects the stimuli and information to be processed in the cerebral cortex (Fortenbaugh et al, 2017): with regard to its nature/ 
origin, it is classified as voluntary, directed and intentionally maintained by the individual, or involuntary, directed more by the stimulus itself than by its aspirations. Regarding the direction of the attentional focus, it is classified as internal, focused on the individual's subjective processes, or external, almost always sensory in nature and focused on the universe that surrounds them. As for the way it is operationalized, it can be defined as selective (ability to respond to one stimulus at the expense of another); alternating (ability to move the attentional focus from one stimulus to another); divided (ability to respond to more than one stimulus at the same time) and, finally, sustained (ability to maintain the attentional focus for longer periods) (Fortenbaugh, DeGutis, \& Esterman, 2017).

Action video games, in turn, are a type of entertainment that exposes the player to a large amount of sensory stimuli, in addition to requiring cognitive ability and motor response that is almost always fast and accurate. Games in this category differ from others precisely in the intensity of these elements, representing the apex of the relationship between psychomotor ability, challenges posed by the video game and intense audiovisual elements of a transitory nature (Bediou et al., 2018). Probably because of these characteristics, action video game players (AVGPs) demonstrated better performance in several aspects of attention when compared to non-action video game players (NAVGPs) (Cardoso-Leite et al., 2016; Föcker, Cole, Beer, \& Bavelier, 2018; Kozhevnikov, Li, Wong, Obana, \& Amihai, 2018). AVGPs register, for example, better attentional control and better ability to switch tasks and inhibit distractors (Cardoso-Leite et al., 2016).

However, two qualitative aspects of the attention system can also play a relevant role in the attention of AVGPs: the predisposition to private self-awareness, that is, in focusing attention on one's emotions and thoughts, personality traits, attitudes and perceptions about oneself (Loyal, Faria, \& DeSouza, 2019)); and the ability to focus attention on the present moment, with monitoring of internal and external events to the individual (Brown \& Ryan, 2003).

In relation to private self-awareness, turning attention to oneself constitutes a higher-order mode of metacognition, representing monitoring and evaluation of internally generated information. Furthermore, it has an essentially paradoxical character: it can be associated with both positive and negative aspects of psychic functioning (DaSilveira, DeSouza, \& Gomes, 2015). It is then composed of two factors: self-reflection, or the ability to monitor stimuli from the internal environment; and insight, or the sense of clear and real understanding of these stimuli (DaSilveira, DeCastro, \& Gomes, 2012; Grant, Franklin, \& Langford, 2002). Note that, although private self-awareness is defined as a trait and, therefore, an individual's natural predisposition, the manner and regularity with which a person turns their attention to themselves may vary from person to person (DaSilveira et al., 2012 ). It is possible then that individual differences in the way and regularity with which this process occurs are related to changes in the attentional process of AVGPs in the measure of the frequency with which they interact with the game.
Regarding the attention focused on the present, would it be reasonable to consider that AVGPs would show differences in their ability and regularity to maintain this focus when compared to NAVGPs? To answer this question, it is necessary to consider that a large part of cognitive and motor processes work in everyday life in a kind of "autopilot", that is, without any attentional focus on them (Brown \& Ryan, 2003; Eysenck \& Keane, 2017). Consequently, two characteristics of this automatism can make it difficult, if necessary, to change everyday actions. The first is that the more automatic, the more unconscious the action performed, which makes it difficult to perceive any inappropriate act. The second is that these processes, once learned, become implicit memory (often formed without involving conscious knowledge of what was learned), which makes them difficult to change (Eysenck \& Keane, 2017). Furthermore, automatic behavior, by decreasing the time between stimulus and response, is associated with behavioral dysregulation and impulsive attitudes, that is, with quick and unintentional reactions, which disregard possible negative consequences of actions (Brown \& Ryan, 2003).

Attention to the present, in turn, allows regulation of impulsiveness by monitoring events from moment to moment, increasing the time between stimulus and response (Brown \& Ryan, 2003) and enabling more conscious choices that avoid perpetuating dysfunctional patterns of conduct. Such healthy monitoring makes the individual more able to observe the environment around them and themselves, pay attention to their own behavior, reactions, thoughts and emotions while they are still happening and, based on that, make the necessary changes (Brown \& Ryan, 2003; DaSilveira et al., 2015). In this sense, attention to the present is associated with insight and together these factors are predictors of psychological well-being (Harrington \& Loffredo, 2010).

In the context of this study, it is of central importance to assess the predisposition of individuals to focus their attention on the present moment, which has been carried out in researches on mindfulness. The mindfulness construct refers to the attentional ability to monitor present experiences while maintaining an attitude of acceptance and non-judgment to these experiences (Bilevicius, Smith, \& Kornelsen, 2018; Brown \& Bryan, 2003; DaSilveira et al., 2012). More specifically, this study is interested in the attentional aspect of the mindfulness construct, that is, the participants' ability to monitor internal and external events from moment to moment. This aspect is assessed by the Mindfulness and Awareness Scale (MAAS) (Brown \& Ryan, 2003). It is a one-dimensional scale, specifically designed to measure how well the respondent works in the so-called "autopilot" mode (Barros et al., 2015; Bilevicius et al., 2018; Brown \& Ryan, 2003).

Returning to the question about the association between the habit of playing video games regularly and changes in the ability to focus attention, it is important to finally consider two factors: (1) the type of interaction that the video game offers the player, possibly training them to make decisions more automatically by demanding great psychomotor performance and very fast decision-making (Bediou et al., 2018); 
(2) evidence that AVGPs demonstrate more ease in automating attentional tasks when compared to NAVGPs (Föcker et al., 2018). Would these two factors together lead players to function more in "autopilot" mode in their everyday life compared to non-players?

Understanding the relationship between interaction with action video games and the two attentional aspects considered in this research (private self-awareness and attention to the present moment) can be especially relevant in the university context. Both private self-awareness and attention to the present moment constitute means of psychological self-regulation, in addition to determining how the individual perceives themselves and the environment around them (Brown \& Ryan, 2003; DaSilveira et al., 2012, 2015). In this way, they can impact cognitive functioning in a demanding environment such as the academic setting.

Therefore, the objective of this study was to verify the relation between the number of hours of interaction with action video games and the self-awareness and attention to the present moment. Considering the characteristics of these two aspects and the particularities of action video games, the hypothesis is that the amount of weekly hours interacting with this type of game has a negative relationship both with private self-awareness and its subfactors and with attention to the present moment.

\section{Method}

\section{Participants}

University students from a public higher education institution in the Southeast region of Brazil, aged between 18 and 29 years, participated in the research. Reporting of any previously diagnosed clinical attention disorder was considered an exclusion criterion. The sample was obtained by convenience, reaching 1,400 individuals. Of these, 11 were excluded for reporting age above 29 years and another 74 people for mentioning clinical attention change. Thus, the final sample consisted of 1,315 participants $(50.9 \%$ identified themselves as female) enrolled in courses in the areas of Humanities (32.2\%), Exact Sciences (35.2\%) and Biological Sciences (32.2\%). The mean age of participants was 21.6 years $(S D=2.7)$. Among the respondents, most were in social classes B2 $(n=386,29.4 \%)$ and C1 $(n=297,22.6 \%)$. On the other hand, classes D and E had the lowest percentage of respondents $(n=74,5.6 \%)$. Finally, in order to establish comparative parameters, those participants who reported interacting with action video games for more than three hours a week were considered AVGPs $(n=130)$. On the other hand, NAVGPs were those who reported not interacting at all with this type of game $(n=681)$.

\section{Instruments}

A total of four instruments were used in the study. Each of them is described below:

\section{Questionnaire on personal and sociodemographic data-QDPS}

Information related to personal data was obtained through a questionnaire that included questions such as age, period in college, marital status, ethnicity, etc. Sociodemographic data were collected through a questionnaire based on the model of the Brazilian Economic Classification Criteria of the Brazilian Association of Research Companies (ABEP, 2015) to determine the social class of the participants. The model suggests a point distribution system linked to the number of comfort items that the participant reports having (number of cars and number of bathrooms at home, for example), access or not to basic infrastructure (piped water and paved street) and the level of education of the head of the family. This model divides respondents into six distinct segments, going from the highest social class to the lowest economically: $\mathrm{A}, \mathrm{B} 1, \mathrm{~B} 2, \mathrm{C} 1, \mathrm{C} 2$ and DE.

\section{Entertainment and Digital Information Usage Questionnaire (QUEID)}

It is a questionnaire with 10 multiple-choice questions developed by the researchers for this study. Some examples of questions include: How long do you typically play electronic games weekly (on consoles, mobile phones, tablets, computers, etc.)? Approximately how often do you watch movies and/or series on your computer, tablet or cell phone?

Among the questions presented, 9 are aimed at both audiences (video game players and non-players), in which the participant chooses options that best describe their study and reading habits, relationship with information technology and habits with digital entertainment. In addition to these, there is a question aimed at video game players which asks how long they interact weekly with the following video game categories: action, adventure, sports, simulation and racing, fighting, Massive Multiplayer Online Role-Playing Game (MMORPG), strategy and casual.

\section{Mindful Attention and Awareness Scale(MAAS) (Brown \& Ryan, 2003)}

The Mindful Attention and Awareness Scale (MAAS) is a one-dimensional scale, specifically focused on the attentional facet of mindfulness, that is, attention to the present, moment by moment monitoring the environment, both internal and external (Barros et al., 2015; Bilevicius et al., 2018; Brown \& Ryan, 2003). It consists of 15 items that indicate the frequency with which the individual experiences each of the situations described (Example: I could experience some emotion and only become aware of it sometime later). The answer options are on a Likert scale ranging from 1 (almost always) to 6 (almost never). Higher scores indicate higher levels of attention to the present moment. The scale was adapted for Brazil, obtaining a satisfactory level of internal reliability ( $\alpha=0.83)$, equivalent to the level of the original scale ( $\alpha=0.87$ ) (Barros et al., 2015). 


\section{Self-Reflection and Insight Scale (SRIS) (Grant et al., 2002).}

The Self-Reflection and Insight Scale has a bifactorial structure, with 12 questions related to self-reflection (for example: I frequently examine my thoughts), that is, the predisposition to turn attention to oneself, and 8 related to insight (for example: I usually have a pretty clear idea of why I've been behaving in a certain way), i.e. the degree of understanding, evaluation and expression of one's thoughts, feelings, emotions, etc. (Grant et al., 2002). Possible answers are distributed on a 5-point Likert scale, ranging from 1 (strongly disagree) to 5 (strongly agree). The SRIS was adapted for Brazil with a satisfactory internal reliability rate (Self-Awareness $\alpha=0.90$, Insight $\alpha=0.82$ ), dimensions close to the original scale (Self-Awareness $\alpha=0.91$, Insight $\alpha=0.87$ ) (DaSilveira et al., 2015).

\section{Procedure}

Data collection. The data collection procedure took place at two times in 2019. The first one was in person and took place in the first semester with the application of instruments in paper-and-pencil format, collectively, in the classrooms of the participants (university students). In this case, the applicator explained the response procedure of the instruments and the main objectives of the research. In case of acceptance, each participant received the Informed Consent Form (ICF). Only after signing it, participants had access to the instruments, in the following order: (1) QDPS, (2) QUEID, (3) MAAS and (4) SRIS. The entire collection procedure took place in an average of 20 minutes in each classroom.

The second collection moment took place online, in which respondents were invited to participate by e-mail. For this, each participant had to agree with the ICF by checking the corresponding option, in addition to informing whether or not they were part of the research's target audience. In case of a negative answer to any of these questions, they were directed to a thank you screen that ended the survey. In case of a positive answer, the participant was directed to consecutive screens to fill in the instruments in the same order as the face-to-face collection: (1) QDPS, (2) QUEID, (3) MAAS and (4) SRIS. Each instrument corresponded to a screen or sets of different screens, and it was only possible to proceed after completing all the questions. In case of doubt or error in filling in, the participant could go back and fill in again what was necessary. At the end of the collection, the participant was thanked for their participation and the research was concluded. This research complied with the ethical guidelines established by Resolution CNS 466/12 and had its execution approved by the Research Ethics Committee of [information suppressed for manuscript submission].

Data analysis. The collected data were analyzed using the SPSS 20.0 and $R$ 3.4.4 statistical software. It was found that the sample size used in this study meets the criteria of a type I error of $5 \%$, and a test power of $80 \%$. After that, a descriptive analysis of the data was performed using statistical measures such as frequency, mean, mode and median. Then, to achieve the established objectives, these same data were submitted to the following statistical techniques: Shapiro-Wilk normality test, Kruskal-Wallis test and Dunn's Post-Hoc test. Furthermore, the correlation index $r$ was calculated to obtain the magnitude of the effects obtained.

\section{Ethical Considerations}

This research complied with the ethical guidelines established by Resolution 466/2012 of the National Health Council and its execution was approved by the Research Ethics Committee of the Universidade Federal do Espírito Santo (CAAE No. 09097818.4.0000.5542). Participation in the research was voluntary and anonymity guaranteed. To participate, respondents had to accept the Informed Consent Form (ICF). Respondents could interrupt their participation at any time, withdrawing their consent without causing them any harm. Due to the nature of the research, the risks for participation were considered minimal. The collected data, in turn, are kept confidential, used only for the statistical analysis in this study.

\section{Results}

Of the total survey participants $(n=1,315), 79.9 \%$ $(n=945)$ reported playing video games, regardless of the time they interact with it or the platform they use. In relation to the action video game, $12.2 \%$ of the participants $(n=130)$ stated that they played more than 3 hours a week. These and other data on the relationship of participants with video games are presented in Table 1.

Then, the scores corresponding to attention to the present moment and private self-awareness, in addition to the self-reflection and insight subfactors, were submitted to the Shapiro-Wilk normality test. The test, in turn, found a non-normal distribution of these variables in the sample, which led to the use of the following non-parametric tests: Kruskal-Wallis test and Dunn's Post-Hoc test (the level of significance was set at $p<0.05$ ).

To perform the Kruskal-Wallis Test, the dependent variables were attention to the present moment and private self-awareness (as well as its self-reflection and insight subfactors). On the other hand, the weekly hours of interaction with video games were considered as independent variables. Regarding self-reflection, there was a difference between those who interact more than three hours a week with action video games (AVGPs) ( $M$ $=47.5, S D=8.2)$ and those who interact with this type of entertainment between 1 and 3 hours a week $(M=46.0$, $S D=8.3)$. That is, the first group had a lower mean score when compared to the second $\left[\chi^{2}(3)=7.9 ; p=0.05, r\right.$ $=0.08$ in the Kruskal-Wallis test]. Private self-awareness and the insight subfactor, in turn, showed no significant difference between the scores recorded when related to time of interaction with action video games [private self- 
awareness: $\chi^{2}(3)=3.7 ; p=0.29$, in the Kruskal-Wallis test; insight: $\chi^{2}(3)=4.9 ; p=0.178$ in the Kruskal-Wallis test]. Considering the attention to the present moment, in turn, the difference between the scores obtained by AVGPs $(M=59.2, S D=12.2)$ and NAVGPs $(M=55.4, S D=13.8)$ was significant $\left[\chi^{2}(3)=11.1 ; p=0.01, r=0.10\right.$ in the
Kruskal-Wallis test], with the first group recording a higher mean than the second.

Finally, to complement the statistical model and identify which pairs of categories are significantly different, Dunn's PostHoc test was used. The means obtained in each attentional aspect and the identified pairs of categories can be seen in Table 2 .

Table 1

Descriptive analysis of data regarding participants' interaction with video games

\begin{tabular}{|c|c|c|c|}
\hline Characteristic & Category & $N$ & $N \%$ \\
\hline \multirow{4}{*}{ Time playing video games weekly } & Never & 370 & $28.1 \%$ \\
\hline & Less than 1 hour & 246 & $18.7 \%$ \\
\hline & Between 1 and 3 hours & 246 & $18.7 \%$ \\
\hline & More than 3 hours & 453 & $34.5 \%$ \\
\hline \multirow{4}{*}{$\begin{array}{l}\text { Time playing action video } \\
\text { games weekly }\end{array}$} & Never & 681 & $63.9 \%$ \\
\hline & Less than 1 hour & 153 & $14.4 \%$ \\
\hline & Between 1 and 3 hours & 102 & $9.6 \%$ \\
\hline & More than 3 hours & 130 & $12.2 \%$ \\
\hline \multirow{4}{*}{$\begin{array}{l}\text { Time playing adventure video } \\
\text { games weekly }\end{array}$} & Never & 724 & $67.9 \%$ \\
\hline & Less than 1 hour & 130 & $12.2 \%$ \\
\hline & Between 1 and 3 hours & 86 & $8.1 \%$ \\
\hline & More than 3 hours & 126 & $11.8 \%$ \\
\hline \multirow{4}{*}{$\begin{array}{l}\text { Time playing sports, simulation } \\
\text { and/or racing video games weekly }\end{array}$} & Never & 806 & $75.6 \%$ \\
\hline & Less than 1 hour & 127 & $11.9 \%$ \\
\hline & Between 1 and 3 hours & 79 & $7.4 \%$ \\
\hline & More than 3 hours & 54 & $5.1 \%$ \\
\hline \multirow{4}{*}{$\begin{array}{l}\text { Time playing fight video } \\
\text { games weekly }\end{array}$} & Never & 838 & $78.6 \%$ \\
\hline & Less than 1 hour & 157 & $14.7 \%$ \\
\hline & Between 1 and 3 hours & 46 & $4.3 \%$ \\
\hline & More than 3 hours & 25 & $3.3 \%$ \\
\hline \multirow{4}{*}{$\begin{array}{l}\text { Time playing MMORPG video } \\
\text { games weekly }\end{array}$} & Never & 783 & $73.5 \%$ \\
\hline & Less than 1 hour & 85 & $8.0 \%$ \\
\hline & Between 1 and 3 hours & 88 & $8.3 \%$ \\
\hline & More than 3 hours & 109 & $10.2 \%$ \\
\hline \multirow{4}{*}{$\begin{array}{l}\text { Time playing strategy video } \\
\text { games weekly }\end{array}$} & Never & 730 & $68.5 \%$ \\
\hline & Less than 1 hour & 142 & $13.3 \%$ \\
\hline & Between 1 and 3 hours & 100 & $9.4 \%$ \\
\hline & More than 3 hours & 94 & $8.8 \%$ \\
\hline \multirow{4}{*}{ Time playing casual games weekly } & Never & 531 & $49.8 \%$ \\
\hline & Less than 1 hour & 292 & $27.4 \%$ \\
\hline & Between 1 and 3 hours & 158 & $14.8 \%$ \\
\hline & More than 3 hours & 85 & $8.0 \%$ \\
\hline
\end{tabular}


Table 2

Attention to the present moment, private self-awareness, self-reflection and insight (means and standard deviations), all related to weekly interaction time with action video games. Kruskal-Wallis test, where the level of significance was set at $p<0.05$

\begin{tabular}{|c|c|c|c|c|c|}
\hline \multicolumn{6}{|l|}{ Attention to the Present Moment } \\
\hline Time playing action video games weekly & $M$ & $S D$ & $g l$ & $\chi^{2}$ & $p$ \\
\hline Never & $55.4_{a}$ & 13.6 & \multirow{4}{*}{3} & \multirow{4}{*}{11.1} & \multirow{4}{*}{$0.01 *$} \\
\hline Less than 1 hour & $57.4_{\mathrm{ab}}$ & 13.5 & & & \\
\hline Between 1 and 3 hours & $56.8_{\mathrm{ab}}$ & 14.1 & & & \\
\hline More than 3 hours & $59.2 \mathrm{~b}$ & 12.2 & & & \\
\hline \multicolumn{6}{|c|}{ Private Self-Awareness (SRIS) } \\
\hline Time playing action video games weekly & $M$ & $S D$ & $g l$ & $\chi^{2}$ & $p$ \\
\hline Never & 72.4 & 11.0 & \multirow{4}{*}{3} & \multirow{4}{*}{3.7} & \multirow{4}{*}{0.29} \\
\hline Less than 1 hour & 71.6 & 11.0 & & & \\
\hline Between 1 and 3 hours & 70.6 & 10.5 & & & \\
\hline More than 3 hours & 71.7 & 11.1 & & & \\
\hline \multicolumn{6}{|c|}{ Self-reflection (SRIS) } \\
\hline Time playing action video games weekly & $M$ & $S D$ & $g l$ & $\chi^{2}$ & $p$ \\
\hline Never & 47.8 & 8.2 & \multirow{4}{*}{3} & \multirow{4}{*}{7.9} & \multirow{4}{*}{0.05} \\
\hline Less than 1 hour & $46.7_{b}$ & 8.2 & & & \\
\hline Between 1 and 3 hours & $46.0_{b}$ & 8.3 & & & \\
\hline More than 3 hours & $46.5_{\mathrm{ab}}{ }^{\circ}$ & 9.2 & & & \\
\hline \multicolumn{6}{|c|}{ Insight (SRIS) } \\
\hline Time playing action video games weekly & $M$ & $S D$ & $g l$ & $\chi^{2}$ & $p$ \\
\hline Never & 39.1 & 13.4 & \multirow{4}{*}{3} & \multirow{4}{*}{4.9} & \multirow{4}{*}{0.178} \\
\hline Less than 1 hour & 41.6 & 11.7 & & & \\
\hline Between 1 and 3 hours & 39.8 & 11.9 & & & \\
\hline More than 3 hours & 38.4 & 12.6 & & & \\
\hline
\end{tabular}

Note: Different subscript values indicate significant differences between means. Average pairs that do not share the same letter are significantly different.

\section{Discussion}

The higher self-reflection score of those who never interact with action video games (NAVGPs) compared to those who interact between 1 and 3 hours a week with this category of games partly confirmed the research hypothesis, that is, that there would be a negative relationship between the self-reflection subfactor and the habit of interacting with action video games. The very low effect size value $(r=0.08)$ (Funder \& Ozer, 2019), however, indicates that this finding should be considered with caution. Even so, this result can be explained as a consequence of a possible self-regulating function of self-reflection, which would allow the player to consciously control the time of interaction with the game, voluntarily interrupting this activity to perform other tasks in their daily life.

In fact, this role of self-reflection as a self-regulator was suggested by Leal, Faria and DeSouza (2019) in their study of alcohol consumption among young people. In this case, high scores on the two subfactors of private self-awareness (self-reflection and insight) were associated with reduced alcohol consumption. Although alcohol consumption is not exactly similar to the consumption of an action video game, it can be suggested that the self-regulating function of self-reflection also explains the shorter interaction time with the game. The literature in the area points to an equivalence between the neurological processes underlying these two behaviors, such as structural and functional changes in areas of the brain responsible for behavioral control and inhibition, emotional regulation, decision making and, mainly, changes in the reward and dopaminergic system (Han et al., 2011).

On the other hand, it is interesting to note that there was no significant difference between insight and number of hours playing action video games $\left[\chi^{2}(3)=4.9 ; p=0.178\right.$ in the Kruskal-Wallis test]. Therefore, the understanding of the self-reflection subfactor as a self-regulation tool must be observed with caution, since it is usually the insight that is associated with adaptive behaviors that provide well-being (Harrington \& Loffredo, 2010).

Perhaps what can better elucidate this inverse relationship between self-reflection and interaction time with action video games is the impact of this game category on the participants' attentional behavior. There is evidence that action video games are able to alter attention at a behavioral 
level by considerably decreasing, for example, the vertical distribution of gaze fixations in visual searches on a computer screen after 10 training sessions of one hour each in games like this (Azizi, Abel, \& Stainer, 2017). Likewise, playing regularly and for a long period could condition this individual to a lesser predisposition to turn attention to themselves, which would be reflected in lower scores in the self-reflection subfactor. This happens because the action video game constitutes a form of entertainment that calls complex and intense attentional processes to an object external to the individual (Bediou et al., 2018), which could influence self-reflection over time, even though it represents a dispositional attentional component (Harrington \& Loffredo, 2010). In fact, considering the age range of the sample in this study (18 to 29 years old), it is likely that participating AVGPs have interacted with action video games for many years. In Brazil, for example, a considerable portion of players $(10 \%)$ is between 16 and 19 years old (Sioux, 2021). It is relevant then to think that the time playing action video games is enough to modulate the players' self-reflection. On the other hand, childhood and adolescence correspond to the brain's maturation phase, with emphasis on areas involved in attention (Murphy et al., 2016). The interaction with video games could then influence this maturation, influencing neural networks related to attentional processes according to the demand of each game and, therefore, influencing the tendency towards private self-awareness of the AVGP.

It is noteworthy that this relationship between action video games and self-reflection was not linear, that is, the result did not show that the more play, the lower the self-reflection. That is, there was no significant difference between NAVGPs and AVGPs. What can be inferred from this is that interacting with this type of game for more than three hours a week could reduce its deleterious effect on self-reflection, thus representing an improvement in this aspect at the level of those who never interact with action video games. This can occur due to the improvement in attentional aspects related to the action video game, which could even influence self-reflection after a certain amount of interaction (Bediou et al., 2018). New research, however, is needed to confirm this hypothesis.

A significant difference was also found in attention to the present moment related to the time of interaction with action video games $\left[\chi^{2}(3)=11.1 ; p=0.01, r=0.10\right.$ in the KruskalWallis test]. In this case, AVGPs performed better $(M=59.2$, $S D=12.2)$ when compared to NAVGPs $(M=55.4, S D=13.8)$. This result refutes the research hypothesis of lower attention to the present moment in AVGPs than in NAVGPs. Two factors motivated this hypothesis: the fact that the MAAS, when assessing respondents' attention to the present moment, provides a measure of how well individuals function or not in "autopilot" mode (Bilevicius et al., 2018; Brown \& Ryan, 2003), and the findings that point to the ease of AVGPs in automating attentional tasks (Föcker et al., 2018). Therefore, it was expected that AVGPs could develop the habit of functioning more automatically in everyday life, with little attention to the present.
A plausible justification for not confirming this hypothesis is that the practice of playing action video games seems closer to a formal meditative practice, especially in relation to the state of flow observed in some types of meditation (Kozhevnikov et al., 2018). This state of flux corresponds to the sensation of unusual concentration in some type of activity, leading to the loss of self-awareness, the passage of time and space (Cacioppe, 2017; Kozhevnikov et al., 2018; Scott-Hamilton, Schutte, \& Brown, 2016).

It is noteworthy that the flow predisposes a type of attention focus different from the mindfulness type of attention assessed by the MAAS. In the flow, there is a deep immersion in some activity, with the focus exclusively directed to the execution of the action. In mindfulness practice, however, attention has a more dispersed focus, monitoring moment by moment, both internal and external stimuli from the environment (Cacioppe, 2017). However, despite the differences, there seems to be a direct relationship between the state of flow and the type of attention that mindfulness practice seeks to improve. A study that followed the effects of mindfulness practice in cycling athletes, for example, concluded that both attention to the present moment and entry into a state of flow were benefited (Scott-Hamilton et al., 2016). In this sense, it is possible to suggest that entering a state of flow facilitates attention to the present moment and vice versa.

Interaction with action video games is also associated with this type of flow experience, offering all the requirements for it to happen: it is an immersive activity; offers a sense of control; is an optimized challenge, balancing difficulty and player skill; has clear goals and immediate, unambiguous feedbacks (Kozhevnikov et al., 2018). Considering the relationship between action video games and the flow state, two possibilities can be pointed out: (1) the constant interaction with the games provides a regular flow state experience and improves the player's attention to the present moment in the same way as the practicing mindfulness of the present moment through meditation enhances meditators' ability to flow; (2) action video game players are individuals who already have a more developed attention to the present moment, which favors the state of flow and consequently provides more pleasure when interacting with action video games. In any case, research specifically focused on the state of flow and its relationship to the present moment will be needed, including in this case studies with training with action video games to validate these possibilities.

A complementary explanation for the better attention to the present moment of AVGPs may lie in the neural structure of these individuals. Evidence points to a positive correlation between the degree of involvement with action video games and the level of functional connectivity in the Prominence Network and in the Central Executive Network, both between the two networks and internally in each of them (Gong et al., 2016, 2017). In addition, the study by Bilevicius et al. (2018) indicated a positive correlation between functional connectivity of these networks and high scores on the MAAS.

The Salience Network and the Central Executive Network are associated with cognitive tasks, motor activity 
and information processing (Bilevicius et al., 2018; Gong et al., 2017). In this sense, the first is essential in the detection and processing of cognitive, emotional or homeostatic stimuli, while the second is active in tasks that require attention, working memory and response selection (Chen et al., 2016). The two then interact with each other by supporting attentional processes, which may explain changes observed both in the relationship with action video games and the higher score on the MAAS.

Again, caution is recommended when interpreting the relationship found between attention to the present moment and interaction with action video games. This happens because of the value considered low $(r=0.10)$ (Funder \& Ozer, 2019) in the magnitude of the effect presented.

For future research, we suggest the use of intervention methods with training of AVGPs in action video games and the application of tests or scales that can measure attention to the present moment before and after the training period. In this way, it will be possible to establish whether or not there is a causal relationship between the habit of interacting with this category of games and the best performance in the construct in question. If so, the action video game could become a training tool for improving attention, including in clinical situations that involve a specific deficit in attention to the present moment.

The objective of this study was to verify the relation between the number of hours of interaction with action video games and the self-awareness and attention to the present moment. We then chose to use the MAAS, a one-dimensional scale specifically focused on the attentional aspect of mindfulness (Brown \& Ryan, 2003). However, it may be interesting in future research to evaluate other dimensions of mindfulness, such as non-judgment, for example, in order to investigate whether the result found when relating attention to the present moment and time playing action video games extends to such dimensions.

Finally, another possible limitation of the research was the circumscription of the sample to a single educational institution. It would be interesting in future research to include students from other higher education institutions, both public and private, in order to verify whether there is a difference in the profile related to video game consumption and the attention aspects analyzed. In addition, contextual aspects involving game behavior, such as in-game proxemics and co-presence, although beyond the scope of this study, could be interesting variables to be included in future investigations that opt for an experimental design, with game sessions in-person.

\section{References}

Azizi, E., Abel, L. A., \& Stainer, M. J. (2017). The influence of action video game playing on eye movement behaviour during visual search in abstract, in-game and natural scenes. Attention, Perception, \& Psychophysics, 79(2), 484-497. doi:10.3758/s13414-016-1256-7
Barros, V. V. D., Kozasa, E. H., Souza, I. C. W. D., \& Ronzani,T.M. (2014). Validity evidence of the Brazilian version of the Five Facet Mindfulness Questionnaire (FFMQ). Psicologia: Teoria e Pesquisa, 30(3), 317-327. doi: 10.1590/S0102-37722014000300009

Bediou, B., Adams, D. M., Mayer, R. E., Tipton, E., Green, C. S., \& Bavelier, D. (2018). Meta-analysis of action video game impact on perceptual, attentional, and cognitive skills. Psychological Bulletin, 144(1), 77-110. doi:10.1037/bul0000130

Bilevicius, E., Smith, S. D., \& Kornelsen, J. (2018). Restingstate network functional connectivity patterns associated with the Mindful Attention Awareness Scale. Brain Connectivity, 8(1), 40-48. doi:1089/brain.2017.0520

Brown, K. W., \& Ryan, R. M. (2003). The benefits of being present: Mindfulness and its role in psychological well-being. Journal of Personality and Social Psychology, 84(4), 822-848. doi:10.1037/0022-3514.84.4.822

Cardoso-Leite, P., Kludt, R., Vignola, G., Ma, W. J., Green, C. S., \& Bavelier, D. (2016). Technology consumption and cognitive control: Contrasting action video game experience with media multitasking. Attention, Perception, \& Psychophysics, 78(1), 218-241. doi:10.3758/s13414-015-0988-0

Cacioppe, R. L. (2017). Integral mindflow: A process of mindfulness-in-flow to enhance individual and organization learning. Learning Organization, 24(6), 408-417. doi:10.1108/TLO-06-2017-0063

Chen, Q., Chen, X., He, X., Wang, L., Wang, K., \& Qiu, B. (2016). Aberrant structural and functional connectivity in the salience network and central executive network circuit in schizophrenia. Neuroscience Letters, 627, 178-184. doi:10.1016/j.neulet.2016.05.035

DaSilveira, A. C., DeCastro, T. G., \& Gomes, W. B. (2012). Escala de Autorreflexão e Insight: Nova medida de autoconsciência adaptada e validada para adultos brasileiros [Self-Reflection and Insight Scale: New self-consciousness measure adapted and validated to brazilian adults]. Psico, 43(2), 155-162. Retrieved from https://revistaseletronicas.pucrs.br/ojs/index.php/ revistapsico/article/view/11693/8039

DaSilveira, A. C., DeSouza, M. L., \& Gomes, W. B. (2015). Self-consciousness concept and assessment in self-report measures. Frontiers in Psychology, 6, 930. doi:10.3389/ fpsyg.2015.00930

Eysenck, M. W., \& Keane, M. T. (2017). Manual de psicologia cognitiva [Cognitive psychology: A student's handbook] (J. F. M. Dorvillé \& S. M. M. Rosa, Trans., 7th ed.). Porto Alegre, RS: Artmed.

Föcker, J., Cole, D., Beer, A. L., \& Bavelier, D. (2018). Neural bases of enhanced attentional control: Lessons from action video game players. Brain and Behavior, 8(7), e01019. doi:10.1002/brb3.1019 
Fortenbaugh, F. C., DeGutis, J., \& Esterman, M. (2017). Recent theoretical, neural, and clinical advances in sustained attention research. Annals of the New York Academy of Sciences, 1396(1), 70-91. doi: 10.1111/ nyas. 13318

Funder, D. C., \& Ozer, D. J. (2019). Evaluating effect size in psychological research: Sense and nonsense. Advances in Methods and Practices in Psychological Science, 2(2), 156-168. doi:10.1177/2515245919847202

Gong, D., He, H., Ma, W., Liu, D., Huang, M., Dong, L., ... Yao, D. (2016). Functional integration between salience and central executive networks: A role for action video game experience. Neural Plasticity, 2016, 9803165. doi:10.1155/2016/9803165

Gong, D., Ma, W., Gong, J., He, H., Dong, L., Zhang, D., ... \& Yao, D. (2017). Action video game experience related to altered large-scale white matter networks. Neural Plasticity, 2017, 7543686. doi:10.1155/2017/7543686

Grant, A. M., Franklin, J., \& Langford, P. (2002). The SelfReflection and Insight Scale: A new measure of private self-consciousness. Social Behavior and Personality, 30(8), 821-836. doi:10.2224/sbp.2002.30.8.821

Han, D. H., Bolo, N., Daniels, M. A., Arenella, L., Lyoo, I. K., \&Renshaw,P.F.(2011). BrainactivityanddesireforInternet video game play. Comprehensive Psychiatry, 52(1), 88-95. doi:10.1016/j.comppsych.2010.04.004

Harrington, R., \& Loffredo, D. A. (2010). Insight, rumination, and self-reflection as predictors of well-being. The Journal of psychology, 145(1), 39-57. doi:10.1080/0 0223980.2010.528072

Kozhevnikov, M., Li, Y., Wong, S., Obana, T., \& Amihai, I. (2018). Do enhanced states exist? Boosting cognitive capacities through an action video-game. Cognition, 173, 93-105. doi:10.1016/j.cognition.2018.01.006

Leal, C. K. N., Faria, G. G. B., \& DeSouza, M. L. (2019). Private self-consciousness, self-reflection, insight and alcohol consumption among young people and adults. Psico-USF, 24(4), 633-644. doi:10.1590/141382712019240403

Murphy, J. W., Foxe, J. J., \& Molholm, S. (2016). Neurooscillatory mechanisms of intersensory selective attention and task switching in school-aged children, adolescents and young adults. Developmental Science, 19(3), 469-487. doi: 10.1111/desc. 12316

Scott-Hamilton, J., Schutte, N. S., \& Brown, R. F. (2016). Effects of a mindfulness intervention on sports-anxiety, pessimism, and flow in competitive cyclists. Applied Psychology: Health and Well-Being, 8(1), 85-103. doi:10.1111/aphw.12063

Sioux (2021). Pesquisa Game Brasil 2021. Recuperado de https://www.pesquisagamebrasil.com.br/pt/ebooks/
Radael Rezende Rodrigues Junior is a $\mathrm{PhD}$ of the Universidade Federal do Espírito Santo, Vitória-ES, Brazil.

Livia Rodrigues is a Professor of the Universidade Federal do Espírito Santo, Vitória-ES, Brazil.

Mariane Lima de Souza is a Professor of the Universidade Federal do Espírito Santo, Vitória-ES, Brazil.

\section{Authors' Contribution:}

All authors made substantial contributions to the conception and design of this study, to data analysis and interpretation, and to the manuscript revision and approval of the final version. All the authors assume public responsibility for content of the manuscript.

Associate editor:

Luciana Mourão Cerqueira e Silva

Received: Jun. 08, 2021

1st Revision: Oct. 19, 2021

2nd Revision: Nov. 08, 2021

Approved: Nov. 10, 2021

How to cite this article:

Rodrigues Junior, R. R., Rodrigues, L., \& Souza, M. L. (2022). Video game interaction related to increased present attention in college students. Paidéia (Ribeirão Preto), 32, e3202.doi:https://doi.org/10.1590/1982-4327e3202 